\title{
OS MATERIAIS DIDÁTICOS VEICULADOS PELO MANUAL DO PROFESSOR PRIMÁRIO DO PARANÁ PARA O ENSINO DA MATEMÁTICA NA DÉCADA DE 1960
}

\author{
Reginaldo Rodrigues da Costa \\ Pontifícia Universidade Católica do Paraná \\ reginaldo.costa@pucpr.br
}

Wagner Alexandre do Amaral Secretaria do Estado da Educação do Paraná wagamaral@hotmail.com

\begin{abstract}
RESUMO
O presente texto trata dos materiais didáticos para o ensino da matemática indicados pelo Manual do Professor Primário do Paraná. O questionamento que orientou este estudo foi: quais materiais didáticos e sua concepção de ensino eram indicados pelo Manual do Professor Primário do Paraná para o ensino da matemática nas escolas do estado na década de 1960? Amparado pela perspectiva da história cultural e dos conceitos de representação e apropriação o texto apresenta as orientações e os materiais didáticos indicados para o ensino da matemática na época e confrontados com referenciais como: Backheuser (1946), Albuquerque (1954), Thorndike (1936), Costa (2016), Pinto (2016) e Pinheiro (2013). Foi possível identificar que os recursos e materiais didáticos expressavam uma concepção de ensino ativo e intuitivo, ou seja, o Manual do Professor Primário do Paraná seguia uma tendência que possibilitava ao aluno o contato com objetos que pudessem expressar conceitos e fatos matemáticos.
\end{abstract}

Palavras-chave: Ensino primário. Ensino intuitivo. Materiais didáticos.

\section{THE DIDACTIC MATERIALS PUBLICIZED BY THE PRIMARY TEACHER'S MANUAL OF PARANA FOR THE TEACHING OF MATHEMATICS IN THE 1960S}

\begin{abstract}
The present text addresses the didactic materials for the teaching of Mathematics indicated by the Primary Teacher's manual of Parana. The question that guided this study was: what didactic materials and their conception of teaching were indicated by Primary Teacher's manual of Parana for the teaching of Mathematics in the state schools in the 1960s? Supported by the perspective of cultural history and the concepts of representation and appropriation, the text presents the guidelines and didactic materials indicated for the teaching of Mathematics at the time and confronted with references such as Backheuser (1946), Albuquerque (1954), Thorndike (1936), Costa (2016), Pinto (2016) and Pinheiro (2013). It was possible to identify that the resources and didactic materials expressed an active and intuitive conception of teaching, that is, the Primary Teacher's manual of Parana followed a tendency that enabled the student the contact with objects that could express mathematical concepts and facts.
\end{abstract}

Keywords: Primary education. Intuitive teaching. Didactic materials.

Rev. Iberoam. Patrim. Histórico-Educativo, Campinas (SP), v. 05, p. 1-19, e019021, 2019. 


\section{LOS MATERIALES DIDÁCTICOS PUBLICADOS POR EL MANUAL PRIMARIO PARA PROFESORES DE PARANA PARA LA ENSEÑNANZA DE MATEMÁTICA EN LOS AÑOS 60 RESUMEN}

El presente texto aborda los materiales didácticos para la enseñanza de la matemática que se indican en el manual del maestro de enseño primario de Paraná. La pregunta que guio este estudio fue: ¿Qué materiales didácticos y su concepción de la enseñanza fueron indicados por el Manual del maestro di enseño primario de Paraná para la enseñanza de matemática en las escuelas estatales en la década de 1960? Respaldado por la perspectiva de la historia cultural y los conceptos de representación y apropiación, el texto presenta las pautas y los materiales didácticos indicados para la enseñanza de Matemática en ese momento y confrontados con referencias como Backheuser (1946), Albuquerque (1954), Thorndike (1936), Costa (2016), Pinto (2016) y Pinheiro (2013). Se pudo identificar que los recursos y los materiales didácticos expresaban una concepción activa e intuitiva de la enseñanza, es decir, el manual del maestro de enseño primario de Paraná seguía una tendencia que permitía al estudiante el contacto con objetos que podían expresar conceptos y hechos matemáticos.

Palabras clave: Educación primaria. Enseñanza intuitiva. Materiales didácticos.

\section{LES MATÉRIELS DIDACTIQUES TRANSMIS PAR LE MANUEL DE L'INSTITUTEUR PRIMAIRE DU PARANA POUR L'ENSEIGNEMENT DES MATHÉMATIQUES LA DÉCENNIE DE 1960}

\section{RÉSUMÉ}

Le texte présent examine les matériels didactiques pour l'enseignement des mathématiques indiquée par le Manuel de l'Instituteur Primaire du Parana. La remise en question qui a guidé cette étude était: quels matériels didactiques et leur conception de l'enseignement étaient appropriés par le Manuel de l'Instituteur Primaire du Parana pour l'enseignement des mathématiques aux écoles de l'état à la décennie de 1960? Aidé par la perspective de l'histoire culturelle et des concepts de représentation et l'appropriation, le texte présente les orientations et les matériels didactiques appropriés à ce moment-là pour l'enseignement des mathématiques et confronté avec référenciels comme: Backheuser (1946), Albuquerque (1954), Thorndike (1936), Costa (2016), Pinto (2016) et Pinheiro (2013). Il était possible de conclure que les ressources et les matériels didactiques exprimaient une conception de l'enseignement actif et intuitif, c'est-à-dire, le Manuel de l'Instituteur Primaire du Parana suivait une tendence qui rendait à l'élève le contact avec les objects qui pourraient exprimer des concepts et les faits mathématiques.

Mots-clés: L’éducation primaire. L’enseignement intuitif. Les matériels didactiques. 


\section{(c) $)$ EY}

INTRODUÇÃO

O presente texto é resultante da pesquisa realizada acerca do ensino primário paranaense e o ensino da matemática na década de 1960. Trata-se de uma continuidade de investigação possibilitada pelo uso e exploração de várias fontes que foram obtidas no processo de pesquisa de doutorado concluída em 2013. Essa continuidade se deu pelo fato do conjunto de fontes utilizado no estudo sobre a formação de professores no estado do Paraná no período de 1961 a 1982 se mostrar potencialmente fecundo quanto à possibilidade de eleger outros objetos de estudo, ampliando assim, as narrativas e as escritas da história da educação matemática paranaense.

Dentre as diversas fontes obtidas na época, localizamos dois volumes do Manual do Professor Primário do Paraná. O referido manual se mostrou, após o estudo de doutoramento, potencial no que diz respeito a apontar indícios sobre o ensino da matemática na escola primária paranaense, com também, vestígios de apropriação e circulação de referenciais e fundamentos predominantes da época, ou seja, da década de 1960.

Já fizemos o uso dessa fonte em estudos anteriores a esse (COSTA, 2016), quando pretendíamos investigar as orientações didáticas oficiais sobre o ensino da matemática para a escola primária paranaense. Entendemos que o manual se constitui numa fonte importante por ter sido um mecanismo que, na época, contribuiu com a circulação, entre os professores paranaenses que atuavam no ensino primário, do ideário pedagógico "adotado" pelos órgãos oficiais do estado do Paraná, não só sobre o ensino da matemática na escola primária, mas, de todas as disciplinas que compunham os programas de ensino da época.

Anteriormente o objetivo de investigação, a partir do Manual do Professor Primário do Paraná era de revelar os propósitos que se pretendia alcançar com o ensino da matemática, uma vez que o governo paranaense se empenhou para que o ensino primário estivesse em concordância com a Lei $n^{\circ}$ 4024/61 (COSTA, 2016). Semelhantemente ao estudo anterior, no que se refere ao uso dessa fonte, nos debruçamos sobre ela com o objetivo de identificar que materiais didáticos eram indicados para o ensino da matemática na escola primária, considerando a circulação desse material nas escolas paranaenses e também entre os professores do ensino primário.

Nesse sentido estabelecemos o seguinte problema que norteou a escrita deste texto: Que materiais didáticos eram indicados pelo Manual do Professor Primário do Paraná para o ensino da 
$(\mathrm{cc}) \mathrm{BY}$

matemática nas escolas do estado na década de 1960? Para isso, consideramos os volumes I e II ${ }^{1}$ destinados, respectivamente, à $1^{\mathrm{a}}$ e $2^{\mathrm{a}}$ séries do ensino primário.

\section{O MANUAL DO PROFESSOR PRIMÁRIO DO PARANÁ}

O manual que foi elaborado pelo Centro de Estudos e Pesquisas Educacionais - CEPE em 1963, sob nosso entendimento o manual é mais um dos indícios do empenho do governo paranaense em consolidar os princípios e o objetivos educacionais expressos pela LDB $\mathrm{n}^{\mathbf{0}} 4024 / 61$ consolidando assim o Sistema Estadual de Ensino e, ao mesmo tempo expressa um alinhamento muito estreito entre as ações paranaenses com a política educacional federal da época que objetivava unificar os processos educativos na escola primária brasileira.

Obviamente que, o manual também se destinava a fazer circular o discurso político dos governantes da época, ou seja, um instrumento de circulação do pensamento político e educacional, considerado apropriado pelos dirigentes políticos da época e que, ao mesmo tempo, seria uma representação das concepções da Secretaria da Educação e Cultura, que na época apresentava em seu quadro de gestores, professores que "supostamente" possuíam a expertise necessária para a elaboração e disseminação do ideário pedagógico da época² ${ }^{2}$.

Nas edições ${ }^{3}$ encontradas, neste percurso investigativo, do manual foi identificado na apresentação do mesmo, um discurso do Secretário da Educação e Cultura que, entre outras coisas, explicitava os objetivos pretendidos para o ensino primário paranaense. Nas palavras desse secretário é possível perceber a intenção da veiculação deste material:

A Secretaria de Educação e Cultura institui e está publicando esta coleção denominada "Manual do Professor Primário do Paraná", que se destina a orientar os professores primários do Estado na sua nobilitante missão de ensinar. Será o nosso manual um guia para a execução dos novos programas de ensino, que foram

\footnotetext{
${ }^{1} \mathrm{O}$ manual, inicialmente deveria ser editado para todas séries do ensino primário, somente foram localizados os volumes I e II. Na apresentação da primeira edição do manual, em 1963, o Secretário da Educação e Cultura destaca que o manual serviria de "subsídio na tarefa docente, constitui um conjunto de idéias cujo interesse máximo é o de levar o educador a forma integralmente a criança”. (PARANÁ, 1963, p. 6).

${ }^{2}$ Nos apoiamos nos conceitos desenvolvidos por Chartier (1988) referentes à representação e apropriação, ou seja, ao mesmo tempo que o manual seria um instrumento de representação do pensamento dos dirigentes ele também serviria para fazer circular essas ideias no coletivo do professorado e com isso, se estabelecia, de uma certa maneira, a apropriação desse ideário. Não nos detemos, pelo menos agora, nos conceitos de estratégias e táticas nesse processo de apropriação.

${ }^{3}$ Em nossa pesquisa foi possível localizar duas edições do volume 1, para a $1^{\text {a }}$ série (1963 e 1965), e duas edições do volume 2 para a $2^{\mathrm{a}}$ série (1964 e 1965).
}

Rev. Iberoam. Patrim. Histórico-Educativo, Campinas (SP), v. 05, p. 1-19, e019021, 2019. 


\section{$(\mathrm{cc}) \mathrm{EY}$}

elaborados para o novo curso primário de seis anos recentemente instituído. [...] O "Manual do Professor Primário do Paraná" se constituirá de 6 volumes, correspondendo às 6 séries do novo curso primário do Estado, e terá uma tiragem de 25.000 exemplares, para a distribuição gratuita aos professores primários. [...] Acreditamos que o presente Manual vai ao encontro do desejo do educador - ter em mãos um instrumento real de trabalho, para conduzir, realmente, o aluno pelo caminho do aprendizado. (PARANÁ, 1963, p. 6) ${ }^{4}$. (Figura 1)

Figura 01 - Manual do Professor Primário do Paraná.

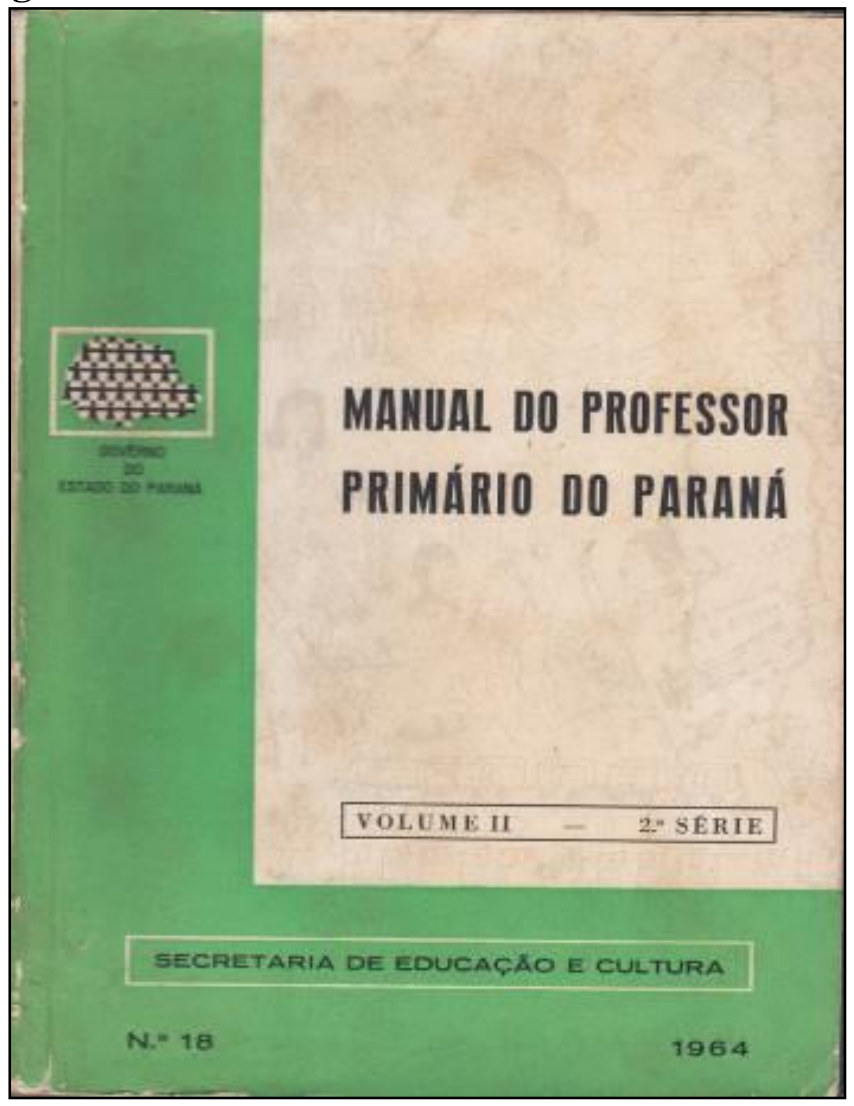

Fonte: Secretaria de Educação e Cultura, 1964.

O manual também apresentava o Decreto no 10.290 que dispunha instruções para o Ensino Primário no Estado, a exposição dos motivos que resultaram na organização do Sistema Estadual de Ensino de 1962 em decorrência da Lei $n^{\circ}$ 4.024/61, a Portaria $n^{\circ}$ 109/63 que aprovou os programas de ensino e as orientações didáticas para o ensino das disciplinas escolares na escola primária paranaense.

\footnotetext{
${ }^{4}$ Mensagem aos professores primários do Secretário de Educação e Cultura Jucundino da Silva Furtado em 1963, 1964 e 1965 contida nos volumes I e II, respectivamente para a 1ª e a $2^{\mathrm{a}}$ séries do ensino primário.
}

Rev. Iberoam. Patrim. Histórico-Educativo, Campinas (SP), v. 05, p. 1-19, e019021, 2019. 


\section{$(\mathrm{cc})$ EY}

Com relação as orientações pedagógicas, o manual trazia os objetivos e os conteúdos considerado mínimos das disciplinas obrigatórias ${ }^{5}$ do Ensino Primário, sugestões de atividades, técnicas e métodos de ensino, práticas pedagógicas com vistas aos objetivos gerais do Sistema Estadual de Ensino paranaense.

\section{O ENSINO DA MATEMÁtica NO MANUAL DO PROFESSOR PRIMÁRIO DO PARANÁ}

A partir da análise realizada dos manuais foi possível identificar concepções que circularam no contexto escolar paranaense sobre o processo de ensino que, predominante, pode ser associado ao escolanovismo (COSTA, 2016). Em relação ao ensino da matemática no ensino primário na época, observamos o seguinte:

O ensino da matemática na escola primária visa fornecer aos alunos os instrumentos básicos para a participação na vida em sociedade e, por conseguinte, dotá-los de conhecimentos utilizáveis na resolução de problemas com que irão defrontar na vida diária. Deve, portanto, o professor aproveitar todas as situações reais que se apresentarem no desenvolvimento dos programas e atividades escolares, para ensinar matemática em situação real. (PARANÁ, 1963, 1964 e 1965).

O manual apresentava ainda, os objetivos específicos para cada uma das duas séries do ensino primário. O volume I destinado à $1^{\text {a }}$ série destacava os seguintes objetivos em relação ao ensino da matemática:

Despertar o gôsto e o interesse pela matemática levando a criança a utilizar com segurança, rapidez e exatidão as primeiras técnicas matemáticas. Desenvolver na criança o raciocínio, a atenção e o espírito de observação, dotando-as das noções necessárias à resolução de problemas na vida prática. (PARANÁ, 1963, p. 65).

Já o volume II, era destinado aos professores que atuavam na $2^{\mathrm{a}}$ série, explicitava a ideia de progressão e continuidade do trabalho iniciado na $1^{\text {a }}$ série e, ao mesmo tempo, destaca a importância da aprendizagem da matemática para a solução de problemas do cotidiano da criança:

Fixar e ampliar as noções adquiridas na $1^{\text {a }}$ série. Desenvolver a capacidade de análise e a de resolver problemas da vida prática. Fixar e ampliar as técnicas das operações fundamentais, favorecendo reações de exatidão e rapidez. Formar

\footnotetext{
${ }^{5}$ Diante da inovação da estrutura curricular pretendida, os manuais apresentam os objetivos, os conteúdos mínimos e as orientações didáticas para o ensino de linguagem, matemática, estudos sociais e ciências naturais.
}

Rev. Iberoam. Patrim. Histórico-Educativo, Campinas (SP), v. 05, p. 1-19, e019021, 2019. 


\section{$(\mathrm{cc})$ EY}

hábitos de exatidão, segurança, ordem e clareza na execução dos cálculos. Gradativamente, levar à abstração do conceito de número. (PARANÁ, 1964, p. 77).

Além dos objetivos, cada volume apresentava uma listagem de temas e conteúdos denominada de "mínimo essencial" para cada série do ensino primário. Em relação à primeira série, o manual, aponta algumas noções fundamentais da matemática relacionadas, como por exemplo, com a quantidade, com o tamanho, com a posição, com a distância, com o tempo e com as medidas. Também era apresentada uma sequência de atividades para a constituição do senso numérico pela criança. Inicialmente essas atividades se destinavam ao "estudo objetivo dos números de 1 a 9", a contagem a partir de materiais e objetos, paralelamente com a leitura e a escrita dos numerais.

Ainda em relação ao número, o manual indicava o estudo dos números até 20, com variações na constituição dos valores para a apropriação e a construção das regras do sistema de numeração decimal, ou seja, orientava o professor a desenvolver atividades de agrupamentos de 10 em 10 com objetos diversos considerando que esta seria a forma mais adequada de construir a noção dos números até 100, na $1^{\text {a }}$ série do ensino primário. Em relação aos saberes numéricos, para a $1^{\text {a }}$ série, o manual destacava orientações para iniciar o trabalho com as operações de adição e subtração, mas, foi possível identificar a a valorização do registro pela criança dos cálculos realizados.

Para o campo numérico e as operações aritméticas, a resolução de problemas era apontada como metodologia para desenvolver algumas noções de tempo e do sistema monetário. Já em relação ao campo geométrico, para a $1^{\mathrm{a}}$ série, o trabalho se resumia ao tratamento e manipulação dos sólidos geométricos como a esfera, o cubo e o cilindro, mas, indicava a possibilidade de se avançar, no que diz respeito às formas contidas nos objetos, passíveis de serem representadas graficamente.

Para a $2^{\mathrm{a}}$ série do Ensino Primário, o manual reforçava a necessidade de dar continuidade ao tratamento das noções de forma intuitiva sobre quantidade, tamanho, posição, distância, tempo e medidas. O campo numérico se ampliava com a orientação de avançar com a numeração até 10.000, objetivando o desenvolvimento das habilidades de leitura e escrita dos numerais e a contagem. Aliada a essa prática havia a orientação de expandir a visão sobre as quatro operações, inclusive com o uso dos números fracionários, principalmente em relação ao campo das medidas,

Rev. Iberoam. Patrim. Histórico-Educativo, Campinas (SP), v. 05, p. 1-19, e019021, 2019. 


\section{(cc) EY}

as grandezas deveriam ser decompostas em partes que representassem o meio (1/2), o terço (1/3), o quarto $(1 / 4)$, etc.

Já em relação ao ensino da geometria, além dos sólidos as figuras geométricas eram indicadas para a realização de atividades de representação gráfica, ou seja, desenho das formas e de objetos que pudessem representá-las. Além disso, era orientado a inserção do estudo das linhas (reta, curva, quadrada e mista) e da reta considerando sua posição (horizontal, vertical e inclinada).

A partir dessa breve descrição é possível perceber que o manual explicitava o que se pretendia quanto ao ensino da matemática nas $1^{\mathrm{a}}$ e $2^{\mathrm{a}}$ séries do ensino primário. Primeiro que, a indicação dos saberes que deveriam ser ensinados com maior ênfase se referia ao campo numérico e, segundo, a orientação que deveria ser desenvolvido um ensino da matemática de forma mais intuitiva. Para tanto, o manual apresentava práticas e sugestões de como o professor poderia contribuir para que os objetivos estabelecidos fossem atingidos, tanto em relação ao ensino primário como um todo quanto para o ensino da matemática especificamente nas escolas primárias paranaenses.

\section{AS ORIENTAÇÕES METODOLÓGICAS SOBRE O ENSINO DA MATEMÁTICA EXPRESSAS NO MANUAL DO PROFESSOR PRIMÁRIO DO PARANÁ}

Boa parte das orientações veiculadas pelo manual se ocupava em fornecer instruções e orientações, aos professores primários, de como ensinar os conteúdos, conceitos e noções matemáticas indicados nos programas de ensino da época, também indicados em cada volume do manual.

As orientações didáticas e as sugestões de atividades eram acompanhadas por uma quantidade significativa de exercícios. Mas, curiosamente, o manual defendia a concepção de que o domínio e a constituição do pensamento abstrato seriam instituídos pela via do concreto (PARANÁ, 1964), ou seja, atividades que promovessem o contato e a manipulação de diversos materiais. Para isso, o manual apresentava dois elementos necessários para que a criança tomasse gosto pela disciplina de Matemática: a objetivação e a motivação. 


\section{$(\mathrm{cc})$ EY}

A objetivação, segundo o manual ${ }^{6}$, seria uma prática apoiada no uso de recursos físicos como coleções, conjuntos de objetos ou ilustrações que permitissem visualizar os conceitos e noções matemáticas que deveriam ser aprendidos, ou seja, fica fortemente expressa a ideia de que o professor deveria fazer uso de materiais didáticos para auxiliar a aprendizagem dos alunos na disciplina de matemática.

Já a motivação se referia à condição da criança estar "interessada e pronta para receber os ensinamentos" (PARANÁ, 1963, p. 68), ou seja, seria o incentivo dado pelo professor a partir de jogos e brincadeiras que manteria "vivo o interêsse infantil, pois, este, agindo como um motor, impulsionará a criança para a frente, tornando-a sempre pronta a receber ensinamentos e a bem desempenhar a sua tarefa" (PARANÁ, 1964, p. 80).

Desta forma, podemos inferir que o manual se configurou num instrumento de circulação dos fundamentos que orientava os processos educativos pertinentes à vaga pedagógica do método intuitivo, que nesta abordagem, a construção dos conceitos e do conhecimento matemático se dariam pela ação dos alunos sobre os objetos e, também, pela percepção e identificação das características captadas a partir dos sentidos que pudessem expressar os fatos matemáticos. Juntamente a isto, identificamos a inserção de atividades lúdicas como forma de atrair o interesse e a participação da criança na aprendizagem da matemática. Mas, o manual expressa uma quantidade significativa de atividades e exercícios, como por exemplo, as "continhas" de cada operação, era por vezes exaustiva e repetitiva.

Sobre esse aspecto, é preciso considerar que essa característica se refere a um princípio importante da perspectiva escolanovistas, conforme podemos observar nas figuras 2 e 3 :

\footnotetext{
${ }^{6}$ Em estudo anterior (COSTA, 2016) foi possível identificar que essas duas concepções tinham origem em materiais que foram elaborados por Thorndike (1936) e Albuquerque (1954) e que circularam em vários outros referenciais da época que tratavam do ensino da aritmética na escola primária brasileira.
}

Rev. Iberoam. Patrim. Histórico-Educativo, Campinas (SP), v. 05, p. 1-19, e019021, 2019. 


\section{$($ (c) $)$ EY}

Figura 02 - Sugestões de Atividades para a $1^{\mathrm{a}}$ série.

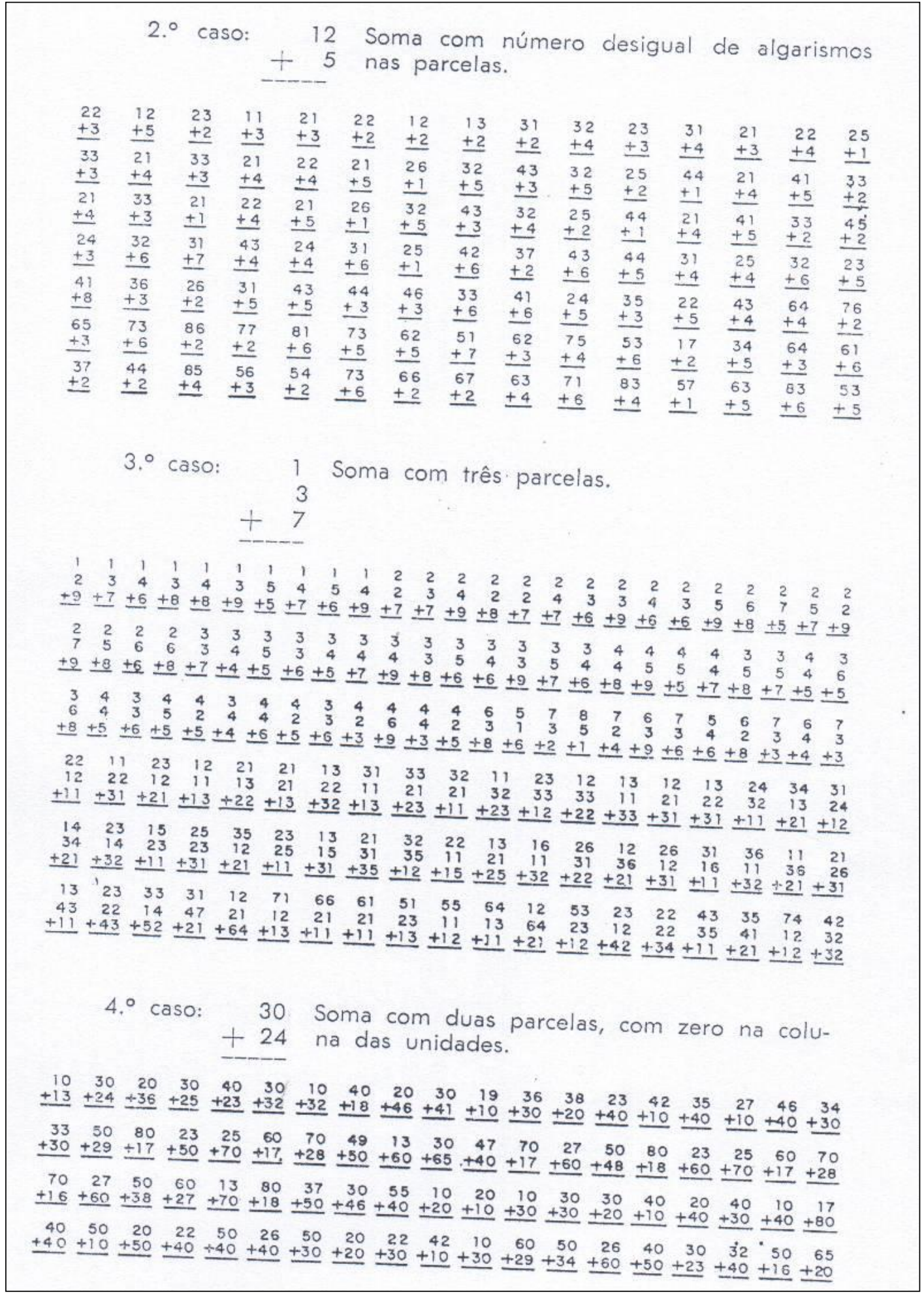

Fonte: Manual do Professor Primário do Paraná - Volume I (1963).

Rev. Iberoam. Patrim. Histórico-Educativo, Campinas (SP), v. 05, p. 1-19, e019021, 2019. 


\section{$($ (c) $)$ EY}

Figura 03 - Sugestões de Atividades para a $2^{\mathrm{a}}$ série.

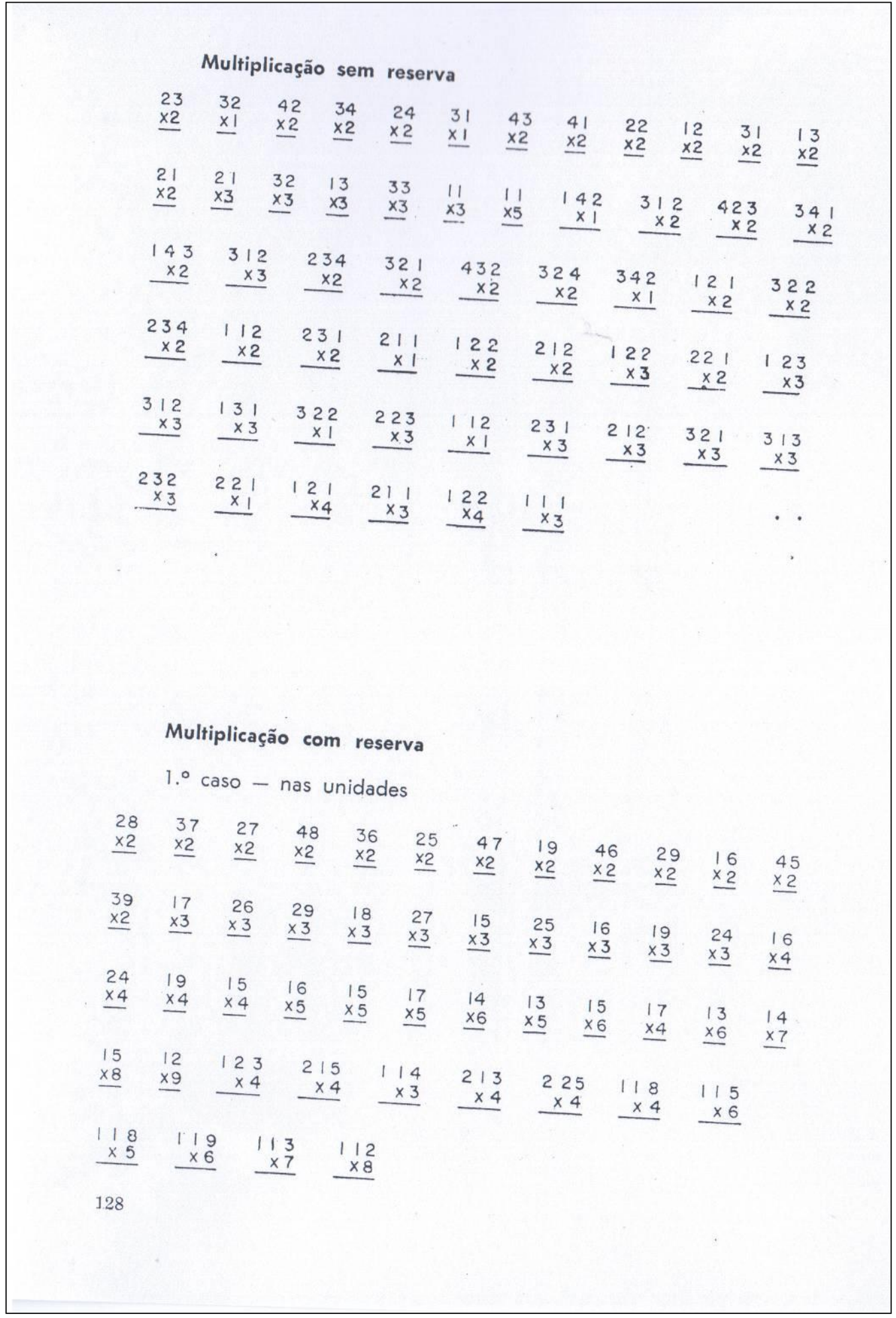

Fonte: Manual do Professor Primário do Paraná -Volume II (1964).

Rev. Iberoam. Patrim. Histórico-Educativo, Campinas (SP), v. 05, p. 1-19, e019021, 2019. 


\section{$(c c)$ EY}

A forma como as operações estão dispostas permite-nos observar um fundamento importante e característico dessa vaga pedagógica, ou seja, o ensino das operações deveria partir do fácil para o difícil pela via do concreto até chegar ao abstrato, ou seja, seria um princípio iniciar o ensino das operações a partir dos fatos mais simples, com o uso de material, e aos poucos inserir fatos mais complexos.

Pinheiro (2013) corrobora conosco em relação à perspectiva de modernização do ensino da matemática influenciado pela perspectiva do movimento da Escola Nova que, visava uma mudança na prática pedagógica para que assumisse um caráter mais objetivo e que valorizasse a experiência sensorial na observação, discriminação, análise e abstração das qualidades de um determinado objeto. Para isso, vários materiais foram elaborados e incorporados ao ensino e, esses materiais ${ }^{7}$ expressavam uma concepção de ensino mais atraente e prático.

Muito evidente nas orientações do manual, a utilização do concreto era considerada via pela qual o aluno poderia chegar aos conceitos abstratos, por exemplo, em relação ao processo de construção do conceito de número, as atividades, sempre com materiais, deveriam iniciar pela identificação de conjuntos, a quantidade, seus elementos, a comparação entre as quantidades de conjuntos distintos, o nome dos números aproximando assim, da representação gráfica (escrita) dos numerais. As orientações incluíam também a indicação do trabalho apoiado na resolução de problemas: primeiro, para isso, a situação proposta pelo professor deveria ser concreta para o aluno e, segundo, que fosse passível de ser representada por objetos, materiais concretos ou por recursos visuais, como cartazes, a fim de possibilitar à criança a compreensão da situação e, consequentemente, representar com auxílio do material a resolução da situação.

Tanto o campo geométrico como o de medida, mesmo que se vislumbrasse uma abordagem integrada com situações do campo numérico, tinham um destaque secundário nas orientações expressas pelo manual, ou seja, ficaram relegados a poucas sugestões de encaminhamentos e atividades quanto ao tratamento metodológico dos conceitos relacionados a cada um deles. Por exemplo, na $1^{\mathrm{a}}$ série o uso do calendário era indicado para a constituição de noções sobre dia, semana e mês, com também, era apontado o uso de um relógio construído, em madeira ou papelão,

\footnotetext{
${ }^{7}$ Segundo Pinheiro (2013) podemos destacar livros e manuais didáticos que tratavam o ensino de forma progressiva, ou seja, cada conceito tinha o momento adequado para ser apresentado considerando a apropriação de um conceito anterior. Para isso o tratamento do ensino deveria ser intuitivo.
}

Rev. Iberoam. Patrim. Histórico-Educativo, Campinas (SP), v. 05, p. 1-19, e019021, 2019. 


\section{$(c c)$ EY}

para o ensino de hora e meia hora. Já sistema monetário era sugerido a manipulação de cédulas e moedas simulando situações de compra e venda de produtos e gêneros alimentícios na sala de aula.

Com relação à geometria o enfoque dado indicava atividades que pudessem estabelecer a correspondência de objetos do cotidiano com os sólidos geométricos que, inicialmente, na $1^{\mathrm{a}}$ série se resumia ao cubo, ao cilindro e à esfera. Explicitava, também, que o trabalho com formas geométricas deveria priorizar a aprendizagem, sempre pela via da percepção visual.

E para finalizar esta seção, destacamos que não identificamos em relação à $2^{a}$ série avanços significativos para o ensino dos campos das medidas e geometria, observamos que os conceitos, relativos a esses dois campos são os mesmos da $1^{\text {a }}$ série e não sugeria um aprofundamento significativo dos conceitos relativos a esses campos.

\section{OS MATERIAIS DIDÁTICOS PARA O ENSINO DA MATEMÁTICA EXPRESSOS NO MANUAL DO PROFESSOR PRIMÁRIO PARANAENSE}

Como já anunciado anteriormente, a concepção veiculada pelo Manual do Professor Primário do Paraná sobre a aprendizagem dos alunos se daria mediante a observância de três aspectos: uso de material concreto, emprego de jogos e brincadeiras e resolução de problemas. Além disso, havia uma aproximação das orientações paranaenses com as publicações de Everardo Backheuser (1946) que, na época, contribuiu para a circulação do ideário pedagógico que defendia um ensino da aritmética, e, por conseguinte à matemática, mais prático que contemplasse "coisas" do cotidiano e, ao mesmo tempo, tivesse como propósito o desenvolvimento das capacidades do raciocínio e da memória (PINTO, 2016).

Nossa análise permitiu estabelecer algumas categorias de materiais indicados pelo Manual do Professor Primário do Paraná. Para a nossa descrição estabelecemos as seguintes características: o tipo de recurso, sua função e a forma de utilização a partir das orientações descritas nos dois volumes do manual.

Inicialmente, identificamos a indicação e a exemplificação de atividades mimeografadas que deveriam ser elaboradas pelo professor e distribuídas aos alunos com a intenção de objetivar ${ }^{8}$ o ensino. As atividades mimeografadas tinham como objetivo trabalhar as noções iniciais da

\footnotetext{
${ }^{8}$ Nesse estudo o significado atribuído à objetivação se refere ao uso de recursos para potencializar a apropriação e a compreensão de um conceito pela criança.
}

Rev. Iberoam. Patrim. Histórico-Educativo, Campinas (SP), v. 05, p. 1-19, e019021, 2019. 


\section{$(c)$ EY}

matemática, ou seja, conceitos relacionados com tamanho (maior, menor e mesmo tamanho), com quantidade (igual, mais e menos), com posição e distância (perto, distante, em cima, atrás, esquerda, direita, etc.). O desenvolvimento dessas atividades deveria ocorrer, segundo o manual, por meio de pintura, recorte e colagem e completar desenhos com quantidades.

O trabalho com medidas, a partir das orientações, poderia ser realizado com atividades envolvendo recipientes de diversos tamanhos, para verificar o volume e a capacidade com a mensuração utilizando água, sempre com ação direta do aluno sobre os objetos utilizados com a intenção de estabelecer a equivalência. Com relação ao comprimento, o uso de instrumentos de medidas e as medidas padronizadas eram contempladas a partir da instituição do metro e dos materiais que pudessem representá-lo como é o caso de barbante, tira de papel ou uma marca equivalente na parede ou no quadro negro. Já em relação ao tempo, o calendário era considerado o material indispensável.

Segundo o manual, para iniciar o processo de numeralização das crianças deveria valer-se de "figuras recortadas, flanelógrafo e ilustrações" (PARANÁ, 1963, p. 74), para atividades relacionadas com a contagem. O recurso visual era muito presente nas orientações e nas atividades propostas que tinham como propósito relacionar o número com o numeral, para tanto orientava-se o professor a construir cartões para realizar associações entre o número (quantidade) e o numeral (símbolo).

Foi possível identificar a indicação de recursos e materiais que não eram estruturados, ou seja, não foram elaborados com propósito atingir um objetivo específico para a aprendizagem. É o caso do uso de recipientes quaisquer (copinhos, baldes, caixinhas) identificado com o numeral que tinha como objetivo associar a quantidade (número) ao numeral (símbolo) utilizando varetas, contas ou palitos de madeira. Ainda em relação ao número, na $1^{a}$ serie, o uso de cartão com número e numeral eram indicados para atividade de o reconhecimento das quantidades e contagem.

Quanto à introdução das operações aritméticas, o manual expressa a concepções e o entendimento de que, antes de iniciar o trabalho com este conteúdo era preciso fazer a criança perceber que um determinado número era formado pela adição de duas ou mais quantidades de diversas formas, para isso, cartazes representando essas combinações eram apontados como o recurso adequado para preparar a criança "para a aprendizagem rápida e suave das combinações fundamentais" (PARANÁ, 1963, p. 80). E se tratando dessas combinações, percebemos uma semelhança dessa perspectiva com as ideias de Everardo Backheuser (1946) que defendia um

\footnotetext{
Rev. Iberoam. Patrim. Histórico-Educativo, Campinas (SP), v. 05, p. 1-19, e019021, 2019.
} 


\section{$(\mathrm{cc})$ EY}

ensino gradativo em relação as operações de adição e subtração na $1^{a}$ série, e as de multiplicação e divisão a partir da $2^{\mathrm{a}}$ série, pois segundo esse autor, esse conteúdo deveria ser desenvolvido seguindo uma escala gradativa de dificuldades indicada, também, pelo Manual do Professor Primário do Paraná (PARANÁ, 1963 e 1964). Essa concepção poderia se materializar, na prática do professor, a partir situações e problemas que gradativamente seriam apresentadas ao aluno, sempre utilizando materiais concretos observando o ritmo e, ao mesmo tempo, preocupar-se com o nível de dificuldade das situações apresentadas. Essa forma de conceber a graduação de dificuldades pode ser observada nos exemplos de situações envolvendo operações aritméticas, nas $1^{\mathrm{a}}$ e $2^{\mathrm{a}}$ séries, nas figuras 2 e 3 , apresentadas anterior à essa seção do texto. Em relação à operação aritmética de multiplicação o manual indicava o uso da Tábua de Pitágoras (PARANÁ, 1964), que tinha como objetivo mostrar os fatos fundamentais da tabuada de multiplicação também de recordar os produtos entre dois números.

Quando ao sistema de numeração decimal (Figura 04), o uso do material concreto era claramente defendido. Seja inicialmente pelo uso de palitos, contas, lápis empregados na constituição da dezena ou pelo uso de materiais didáticos estruturados especificamente para esse fim. Em relação a isso, por exemplo, a Caixa Valor do Lugar, recurso indicado pelo Programa de Assistência Brasileiro-Americana ao Ensino Elementar - PABAEE $^{9}$ e pelo manual serviria ao processo de construção das noções relativas ao sistema de numeração decimal:

Figura 04 - Material para o ensino do Sistema de Numeração Decimal
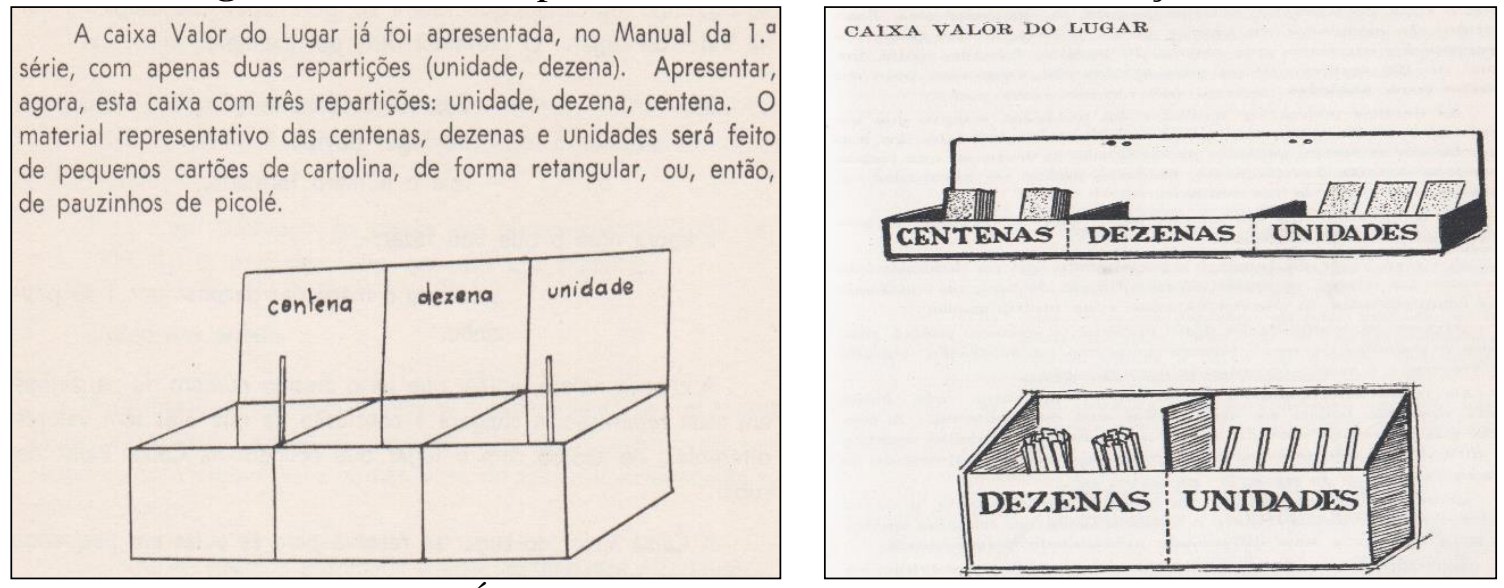

Fonte: PARANÁ, 1963, 1964, 1965. Fonte: PABAEE - PORTO, 1959.

\footnotetext{
${ }^{9}$ Sobre o Programa de Assistência Brasileiro-Americana ao Ensino Elementar - PABAEE, ver artigo "Os Experts dos primeiros anos Escolares: a construção de um corpo de especialistas no ensino da matemática” (In: PINTO, VALENTE, 2016).
}

Rev. Iberoam. Patrim. Histórico-Educativo, Campinas (SP), v. 05, p. 1-19, e019021, 2019. 


\section{$(\mathrm{cc}) \mathrm{BY}$}

A partir disto contatamos que, não somente este, mas vários outros recursos ${ }^{10}$ são comuns, tanto no manual paranaense como também nas publicações da época que eram distribuídas aos professores primários pelo Programa de Assistência Brasileiro-Americano ao Ensino Elementar PABAEE. Para Porto $(1959$, p. 21) "ao usar o material concreto para fins de demonstração a professora deve seguir a mesma ordem que deseja que os alunos usem, quando executarem seu trabalho escrito", ou seja, o material tinha como função habituar e estabelecer a ordem formal do registro na criança. A autora também reforçava que, "a criança se interessa pelas ideias quantitativas e pelas relações numéricas, quando pode percebê-las. E é através da manipulação que ela penetra e descobre as verdades aritméticas" (PORTO, 1959, p. 23). Novamente nossa análise nos permite associar as orientações do manual com ideias escolanovistas relativas ao princípio de ensino ativo, ou seja, priorizar situações de ensino mediadas por recursos e materiais didáticos concretos.

Para o trabalho com geometria, na $1^{\mathrm{a}}$ série a orientação era utilizar material, recursos e objetos do cotidiano da criança que pudessem ser relacionados com os sólidos geométricos, identificando assim semelhanças entre eles: "Levar a criança, pela forma, a conhecer os sólidos geométricos, relacionando-os com objetos conhecidos. Por exemplo: um dado, uma caixa de giz, parecem um cubo; um cano, um lápis sem ponta lembra um cilindro; uma bola tem a forma de uma esfera." (PARANÁ, 1963, p. 97).

Para a $2^{\mathrm{a}}$ série, predominava a ideia do uso de materiais do cotidiano como o caminho para a associação entre forma e objeto, mas, para além disso indicava-se também o uso de papel colorido para recorte de figuras. Havia ainda a indicação de material como "sabão barro, espuma de nylon ou massa plástica” para a modelagem dos sólidos geométricos (PARANÁ, 1964, p. 162). Essa perspectiva nos permite relacionar com os objetivos e atividades de trabalhos manuais objetivando a percepção dos conceitos geométricos.

Mas, a cada conjunto de das orientações que analisamos, reforça a representação da época, em atribuir ao campo numérico maior ênfase no ensino da matemática, os campos geométricos e das medidas ficaram relegados a um aspecto secundário, enfatizando a importância dos números

\footnotetext{
${ }^{10}$ Cartaz Valor do Lugar e o mostrador de quantidades (bolinhas ou tampinhas num total de dez, unidos por um arame) são mais alguns exemplos comuns entre os dois manuais.

11 Rizza Araújo Porto foi professora do Instituto de Educação de Belo Horizonte e Especialista em Ensino da Matemática na Escola Primária. Foi integrante do Departamento de Aritmética do "Programa de Assistência BrasileiroAmericano ao Ensino Elementar - PABAEE”, sediado no Instituto de Educação de Minas Gerais, realizou estágio de estudos na Universidade de Indiana no período de 1956-1957 (COSTA, 2013).
}

Rev. Iberoam. Patrim. Histórico-Educativo, Campinas (SP), v. 05, p. 1-19, e019021, 2019. 


\section{$(c)$ EY}

em detrimento das formas e das medidas, o que é um equívoco, pois a dependência entre eles é muito estreita.

\section{CONSIDERAÇÕES FINAIS}

Ao finalizar esse texto, que tinha a intenção de apresentar os materiais didáticos indicados e veiculados pelo Manual do Professor Primário do Paraná para o ensino da matemática no ensino primário paranaense durante a década de 1960, podemos influir que o Ensino Primário do estado do Paraná refletia, não só a adoção das orientações oficiais elaboradas e divulgadas pelo Ministério da Educação e Cultura na década de 1960 em função da instituição da Lei n 4.2024/61 mas, também o ideário pedagógico do escolanovismo, ainda presente naquela época.

Já em relação ao uso de materiais, o presente estudo permitiu estabelecer uma aproximação das orientações contidas no manual sobre os tipos e o uso dos recursos considerados necessários para aprendizagem matemática com os que eram indicados nas produções destinadas aos professores que eram distribuídos pelo PABAEE. Essas produções voltadas à capacitação e aperfeiçoamento dos professores divulgavam amplamente o uso materiais concretos no ensino da matemática, pois, eles permitiam visualizar, sentir e, segundo a perspectiva escolanovistas, favorecia a criança fazer descobertas relativas aos conceitos e saberes matemáticos ensinados.

Ao finalizar este texto é preciso destacar a ênfase dada sobre a ação manipulativa de objetos pela criança, envolvendo situações reais da sua vida cotidiana; condições essenciais para se atingir os propósitos estabelecidos para a aprendizagem da matemática no ensino primário.

A partir do estudo sobre a orientações expressas no manual, identificamos concepções de ensino e de aprendizagem que se relacionam com uma perspectiva de ensino ativo e intuitivo, características da vaga pedagógica da escola nova. Além disso, foi possível relacionar essas concepções com autores da época, como por exemplo, com os fundamentos expressos por Everardo Backheuser (1946), considerado um especialista da pedagogia escolanovista, destacava em seus manuais pedagógicos a importância de desenvolver um ensino de matemática mais prático e realista, no sentido de ser real para a criança, tendo como princípio fundamental o uso de materiais concretos para concretizar a perspectiva de ensino e de aprendizagem pela via do concreto como forma de ilustrar e tonar perceptível os conceitos matemáticos.

Rev. Iberoam. Patrim. Histórico-Educativo, Campinas (SP), v. 05, p. 1-19, e019021, 2019. 


\section{(cc) EY}

Observamos também uma aproximação das orientações expressas pelo Manual do Professor Primário do Paraná com as propostas de Porto, a partir do material do PABAEE, que reforçava a concepção de um ensino da matemática amparado por materiais concretos. Com o conceito de ensino objetivado que vai ao encontro do entendimento de Irene de Albuquerque (1954) que apoiada também nas perspectivas de Edward Lee Thorndike (1936), concebia um ensino de matemática mediado por objetos que pudessem explicitar e expressar as noções e os conceitos matemáticos de forma gradativa respeitando as capacidades de pensamento da criança.

E por fim, não poderíamos desconsiderar que o próprio manual se configurou num material didático que se prestou cumprir várias funções quanto ao ensino e à aprendizagem. De fora geral, foi um instrumento de representação, veiculação e circulação de ideias pedagógicas que incidiu sobre a prática do professor, pelo menos, no que se refere às intenções dos governantes que era de sistematizar orientações que pudessem colocar o ensino primário paranaense entre os exemplos que explicitassem a observância da Lei no 4.024/61.

Além disso, como material didático, fez circular orientações e propostas para o ensino da matemática pautado numa concepção de ensino mais sistematizada e científica, considerando as aproximações observadas com a concepção do ensino ativo, intuitivo e moderno que já concebe a necessidade de considerar as habilidades e capacidades do aluno ao definir conteúdos, estratégias de ensino e materiais didáticos.

Nesse sentido, podemos entender que o manual como material didático serviria de fonte de “inspiração" para os professores primários pensarem e organizarem seu trabalho pedagógico. Mas, nos resta saber, num estudo posterior, se essas concepções incidiram realmente sobre o ambiente escolar e, principalmente sobre as práticas e a forma de conceber e desenvolver o ensino de matemática nas escolas paranaenses na década de 1960.

\section{REFERÊNCIAS}

ALBUQUERQUE, Irene de. Metodologia da Matemática. Rio de Janeiro: Editôra Conquista, 1954.

BACKHEUSER, Everardo. Como se ensina aritmética. Porto Alegre: Livraria Globo, 1946.

CHARTIER, Roger. A história cultural: entre práticas e representações. Lisboa: Difel, 1988. 


\section{(cc) $\mathrm{BY}$}

COSTA, Reginaldo Rodrigues da. A capacitação e aperfeiçoamento dos professores que ensinavam matemática no estado do Paraná ao tempo do movimento da matemática moderna - 1961 a 1982. Curitiba: CRV, 2013.

COSTA, Reginaldo Rodrigues da. A matemática na escola primária paranaense na década de 1960: orientações metodológicas e aprendizagem. Revista Diálogo Educacional, v. 16, n. 48, p. 423-443 2016.

BRASIL. Senado Federal. Lei de Diretrizes e Bases da Educação Nacional: no 4024/61. Brasília: 1961.

PARANÁ, Secretaria de Educação e Cultura. Manual do professor primário do Paraná. v. 1. 2. ed. Curitiba, 1965.

PARANÁ, Secretaria de Educação e Cultura. Manual do professor primário do Paraná. v. 2. 2. ed. Curitiba, 1965.

PARANÁ, Secretaria de Educação e Cultura. Manual do professor primário do Paraná. v. 2. Curitiba, 1964.

PARANÁ, Secretaria de Educação e Cultura. Manual do professor primário do Paraná. v. 1. Curitiba, 1963.

PARANÁ, Secretaria de Educação e Cultura. O Ensino primário no Paraná: Nova seriação e programas para os grupos escolares e casa escolares. Curitiba, 1962.

PINHEIRO, Nara Vilma Lima. Escolas de práticas pedagógicas inovadoras: intuição, escolanovismo e matemática moderna nos primeiros anos escolares. 2013. 156 f. Dissertação (Mestrado em Educação e Saúde na Infância e na Adolescência) - Universidade Federal de São Paulo - Guarulhos/SP.

PINTO, Neuza Bertoni. Matrizes Pedagógica de manuais que ensinam a ensinar aritmética na escola primária em tempos de escola nova: aproximações e distanciamentos. Revista HISTEMAT - Revista de História da Educação Matemática, v. 1, p. 173-189, 2016.

PINTO, Neuza Bertoni; VALENTE, Wagner Rodrigues (Orgs.). Saberes elementares matemáticos em circulação no Brasil: dos documentos oficiais às revistas pedagógicas 1890 1970. São Paulo: Editora da Física, 2016.

PORTO, Rizza Araújo. Ver, sentir, descobrir a aritmética. Belo Horizonte: PABAEE, 1959.

THORNDIKE, Edward Lee. A nova metodologia da aritmética. Porto Alegre: Livraria Globo, 1936. 